\title{
PRINCIPLES AND CONTENT FOR DEVELOPING A THEORY OF LEARNING
}

By Gale Jensen

Professor of Adult Education, University of Michigan

$T^{\mathrm{n}}$ HIS article is addressed to the adult education practitioner with two objectives in mind. First, the article will identify and elaborate a set of principles which the adult educator can follow in building a functional theory of adult learning. Second, it will identify and describe the kind of content or socio-psychological phenomenon to which such a theory must refer.

1. The adult education practitioner must build a theory which is applicable to the problems of practice be faces with respect to organizing and expediting learning situations for adults. He is continuously involved in situations in which practical difficulties about maximizing adult learning arise. As a consequence, he faces the tasks of analyzing these difficulties, making decisions about what should be done, and then acting upon or carrying out these decisions.

To be functional, his theory must be instigated by the very problems he faces in everyday practice. This doesn't mean that his theory is any less systematic than theory provoked primarily by curiosity. It only means that whatever theory emerges always should be relevant to or have a logical connection with his problems of educational practice.
In brief, his theory must always enable him (1) to engage in analysis that leads to a better understanding of his practical problems, (2) to make more competent decisions about what should be done, and (3) to guide his action toward more effective performance of his job. This means that he should not let his theorizing become so formal or abstract that he is unable to make some conceptual connection between his theory and the intellectual tasks at the heart of his practice, viz., analyzing, deciding upon needed action, and then implementing the decision.

\section{A Part of Himself}

2. The adult education practitioner must "internalize" or make bis theory of adult learning a part of bimself. This is no easy matter because this kind of internalization requires the adult educator to revamp or change his previously acquired perceptions, attitudes, and emotional responses which might inhibit the kind of behavior which represents a psychological and logical extension of his learning theory.

Too often a good theory of learning becomes compartmentalized to the extent that the practitioner's behavior is based on the "hit and miss" ideas 
unconsciously acquired over the years. It is as though he develops a theory of learning and then promptly sets it aside when it comes time to deal with the learning problems found in practical situations.

\section{The Best Verified Findings}

3. A theory of adult learning should be based on the best empirically verified findings available. The research on human learning is now abundant. The task of the adult education practitioner is that of sorting through the available research studies to discover those research problems which raise the same kind of questions he wishes to ask of his theory. Whenever he identifies well-formulated research problems based on theory which conceptually corresponds to his own, he is in a position to acquire some degree of verification or denial of his theory. He must, of course, be capable of evaluating a research study in terms of the adequacy of its design, data collection instruments and procedures, and data analysis.

Whenever a research study is acceptable in terms of the scientific criteria by which it is judged or evaluated, the adult educator possesses systematic empirical evidence about the validity of his theory of adult learning. In this way he discovers which areas or aspects of his theory are empirically strong and which are weak and require further evidence. $\mathrm{He}$ also discovers those areas in which validation rests mainly on intuition and pragmatic experience. These are areas for which systematically acquired empirical evidence is almost or wholly lacking.
While it is more or less inevitable that a practitioner must utilize intuitively and pragmatically established theory, he cannot afford to be satisfied with his state of affairs unless he wishes to live with many practices for which he has no rationale or reason and with problems for which there is no promise of solution.

In brief, the advancement of his practice rests upon his abliity to subject his theory to systematic, empirical testing and validation. This is the only means for assuring continuous and constructive criticism of the ideas which direct his practice.

\section{Advantages of Testing}

4. A theory of adult learning must be revised from time to time in order to formulate more fruitful or adequate conceptualizations about adult bebavior. Systematic, empirical testing uncovers the inadequacies of a theory and requires the invention of new ways for conceiving a particular kind of phenomenon. The hope is that the new conceptualizations will be more effective in the sense that they will explain everything the old ideas did plus something that the old ones did not.

When the adult education practitioner obtains enough systematically collected empirical evidence to identify some of the weaknesses and discrepancies of his theory, he must undertake to revise it. His revisions should attempt (1) to remove those theoretical assertions which his empirical evidence seems to reject; (2) to eliminate those ideas which have little diagnostic or explanatory power; and (3) to resolve inconsistencies 
which appear between different parts of his theory.

The improvement of educational practice is only possible through the improvement of the ideas which direct it. Periodic attempts to revise old and formulate new ideas or concepts about adult learning is, therefore, a necessity for the improvement of adult education practice.

\section{Content for a Theory Of Adult Learning}

In formulating a theory of adult learning, the adult education practitioner is faced with determining the kind of phenomenon to which his theory will refer. His ability to analyze adult learning situations and to project and organize instructional procedures and programs is dependent in part upon the socio-psychological variables he chooses to include in his theory. The choice of phenomenon about which he develops his theory therefore indicates what he will attempt to analyze and what kinds of socio-psychological factors he will employ to control and facilitate adult learning. ${ }^{1}$

1. One kind of phenomenon to which a theory of adult learning should refer concerns the structure and dynamics of face-to-face groups. It is in the setting of the face-to-face group that formal instruction takes place. Generally speaking, we designate this kind of group the classroom or instructional group.

The human relations structure and dynamics that emerge in these groups are very complex. They have a determining effect upon (a) what a class member will learn in a given group and (b) how it is possible for him to learn. Under certain conditions, they are likely to block or hamper learning rather than to facilitate it.

Any theory of learning that does not take account of this kind of phenomenon will be grossly inadequate for analyzing and directing adult education enterprises. The minimal group conditions for good achievement must be known by the adult educator if he is to organize and conduct classes in which adults experience satisfaction and high achievement. This is possible only if his theory of learning is adequate for analyzing and managing the group phenomena which affects adult instruction.

\section{Concern with Social Processes, Structures, Activities}

2. The second kind of phenomenon with which a theory of adult learning should be concerned has to do with the social processes, structures, and activities found in the formally organized social systems in which American adults spend much of their working hours. Instruction or formal learning, for example, takes place within one of these formal social systems. We generally speak of this as a school system. It is through the efforts of these formal organizations that most of adult instruction is planned and implemented, be it church, a school system, military organization, medical establishment, governmental department, or industrial concern.

The needs of these organizations influence greatly the learning goals of adults. What an adult wishes to 
learn is very often generated by his experiences in these organizations. The character of his participation in these systems will determine how well he is able to obtain the income and resources he wants for himself and his family. The character of his participation in these systems also influences what he wishes to learn to maintain himself as a healthy, wellintegrated human being.

These formal social systems generate the motivations which underlie the adult's desire to learn. A theory of adult learning which does not take account of these phenomena is likely to be grossly inadequate for enabling the adult educator to analyze and assess the motivation and curriculum content problems associated with adult instruction.

\section{Personality Organization}

3. The third kind of phenomenon to which a theory of adult learning should refer is that which has to do with personality organization. This will include the phenomenon to which the traditional learning theory refers. In addition, it will include consideration of the kinds of integrations that take place between the cognitive, emotional, and motor aspects of human development.

Very little attention has been paid to the way defense mechanisms develop or are learned. Seemingly, the types of integration that form between cognitive, emotional, and motor learnings are in some way related to the kinds and degree of defense behavior the personality acquires. In many ways, this aspect of a theory of adult learning will be the key to determining what and how a particular adult can learn more adequate behaviors.

\section{Community Participation}

4. A fourth kind of phenomenon has to do with community institutions and ideologies. It is through participation in the life of the community that a person acquires his psychological picture or model of social life. What is appropriate behavior for taking part in the activities of the community as a citizen must be learned. Formal instruction must take account of the social reality which the adult has learned.

Proposed learning objectives which are based on contrary or conflicting ideas about social life are likely to be rejected by him. He knows unconsciously, if not consciously, that if he were to acquire new learnings that are not based on social reality, he is likely to be less, rather than more able, to effectively participate in the affairs of the community. He is unlikely to hold his community position or even survive in some cases.

A theory of adult learning which does not take account of these factors fails to provide the adult educator with a conceptual basis by which he can select and plan instruction and learning situations which are grounded in the social realities about which adults are personally sensitive.

${ }^{2}$ Cf. Jensen, Gale E. Socio-Psychological Analysis of Education Problems. Ann Arbor Publishers: 1957. Pp. 5-6. 